\title{
ANALISA KONDISI FUNGSIONAL PERKERASAN JALAN MENGGUNAKAN METODE PAVEMENT CONDITION INDEX (PCI) (Studi Kasus Jalan Harun Sohar Palembang)
}

\author{
Riyos Bachtiar $^{(1)}$, Revianty Nurmeyliandari ${ }^{(2)}$ \\ revianty.nurmeyliandari@binadarma.ac.id \\ Program Studi Teknik Sipil \\ Fakultas Teknik Universitas Bina Darma Palembang
}

\begin{abstract}
ABSTRAK
Kinerja perkerasan merupakan kondisi perkerasan yang dapat memberikan pelayanan kepada pemakai jalan selama kurun waktu perencanaan tertentu. Penelitian ini bertujuan untuk mengetahui jenis-jenis kerusakan jalan dan nilai kondisi perkerasan jalan sehingga dapat menentukan cara perbaikannya. Penelitian evaluasi kerusakan jalan dilakukan melalui survey visual, yaitu dengan mengukur panjang, lebar, dalam serta luasan dari tiap kerusakan yang terjadi. Setelah data-data di atas diperoleh, maka untuk analisa pengambilan keputusan digunakan metode Pavement Condition Index (PCI).Hasil yang didapat dari analisis data pada kerusakan jalan Letjen Harun Sohar (Palembang), mempunyai nilai PCI yaitu pada area Pos 1 adalah 98.54 (sempurna), sedangkan pada Pos 2 adalah 87.37 (sangat baik) berdasarkan ratting kondisi perkerasan Pavement Condition Index (PCI).
\end{abstract}

Kata kunci : Jenis dan Tingkat Kerusakan Jalan, Pavement Condition Index (PCI).

\section{PENDAhuluan}

Kerusakan jalan merupakan pemasalahan yang kompleks dan merugikan pengguna jalan. Secara umum penyebab kerusakan jalan dapat disebabkan oleh genangan air pada permukaan jalan, frekuensi dan muatan kendaraan yang melebihi batas kemampuan jalan, serta pengawasan yang kurang baik dan pelaksanaan yang tidak sesuai dengan standard yang telah ditetapkan. Prioritas penanganan yang kurang tepat juga menjadi penyebab kerusakan jalan.

Tujuan pemeliharaan jalan adalah untuk mempertahankan kondisi jalan sesuai dengan tingkat pelayanan dan kemampuan pada saat jalan tersebut selesai dibangun dan dioperasikan sampai dengan tercapainya umur rencana yang telah ditentukan. Perkerasan lentur adalah sebuah bentuk struktur yang terdiri dari beberapa lapisan yang menjadi satu kesatuan untuk memikul beban kendaraan yang lewat diatasnya dan bisa menyalurkan beban dari kendaraan tersebut dengan baik dari lapisan paling atas ke lapisan - lapisan yang ada dibawahnya. Sebagai lapis perkerasan,struktur ini diharapkan mampu memikul beban lalu lintas rencana sesuai dengan umur rencana yang telah direncanakan agar tidak mengalami kerusakan - kerusakan yang berarti. Tetapi hampir sebagian besar perkerasan lentur sudah mengalami kerusakan terlebih dahulu sebelum mencapai umur rencananya. Kerusakan pada perkerasan dapat digolongkan menjadi 2 ( dua) bagian, yaitu kerusakan struktural dan kerusakan non struktural.

Kerusakan struktural ialah kerusakan yang menyebabkan berkurangnya kemampuan jalan dalam memikul beban yang melewatinya. Kerusakan non-struktural atau fungsional ialah kerusakan yang hanya menyebabkan berkurangnya tingkat keamanan dan kenyamanan pengendara yang melalui jalan 
tersebut, tetapi tidak mengurangi kemampuan jalan untuk memikul beban yang melewatinya.

$$
\text { Untuk menganalisa kinerja }
$$
fungsional perkerasan dari sebuah ruas jalan dapat digunakan beberapa jenis perameter. Secara subjektif dapat digunakan parameter PCI (Pavement Conditional Index), yang diperoleh dari pengamatan kerusakan, secara visual. Dalam penelitian ini, akan dianalisa kinerja fungsional perkerasan jalan dengan parameter Nilai Kondisi (NK) perkerasan tersebut untuk menentukan jenis pemeliharaan jalan.

\section{TINJAUAN PUSTAKA}

\subsection{Pengertian Jalan}

Jalan adalah prasarana transportasi darat yang meliputi segala bagian jalan, termasuk bangunan pelengkap dan perlengkapannya yang diperuntukkan bagi lalu lintas, yang berada pada permukaan tanah, di atas permukaan tanah, di bawah permukaan tanah dan/atau air, serta di atas permukaan air, kecuali jalan kereta api, dan jalan kabel (Peraturan Pemerintah Nomor 34 Tahun 2006).

Jalan raya adalah jalur - jalur tanah di atas permukaan bumi yang dibuat oleh manusia dengan bentuk, ukuran - ukuran dan jenis konstruksinya sehingga dapat digunakan untuk menyalurkan lalu lintas orang, hewan dan kendaraan yang mengangkut barang dari suatu tempat ke tempat lainnya dengan mudah dan cepat (Clarkson H.Oglesby,1999).

\subsection{Jenis Perkerasan}

Saat ini ada dua jenis konstruksi perkerasan jalan yang umum dikenal, yaitu Konstruksi Perkerasan Lentur (flexible pavement) dan Konstruksi Perkerasan Kaku (rigid pavement).

\subsubsection{Perkerasan Lentur (flexible pavement)}

Yang dimaksud perkerasan lentur (flexible pavement) adalah perkerasan yang umumnya menggunakan bahan campuran beraspal sebagai lapis permukaan serta bahan berbutir sebagai lapisan dibawahnya.Sehingga lapisan perkerasan tersebut mempunyai flexibilitas/kelenturan yang dapat menciptakan kenyaman kendaraan dalam melintas diatasnya. Perlu dilakuan kajian yang lebih intensif dalam penerapannya dan harus juga memperhitungkan secara ekonomis, sesuai dengan kondisi setempat, tingkat keperluan, kemampuan pelaksanaan dan syarat teknis lainnya, sehingga konstruksi jalan yang direncanakan itu adalah yang optimal. Pada perkerasan, beban lalulintas disalurkan ke tanah dasar yang dipadatkan melalui beberapa lapisan.

Adapun lapisan-lapisan tersebut adalah sebagai berikut :

a) Lapisan permukaan.

b) Lapisan pondasi atas.

c) Lapisan pondasi bawah.

d) Lapisan tanah dasar.

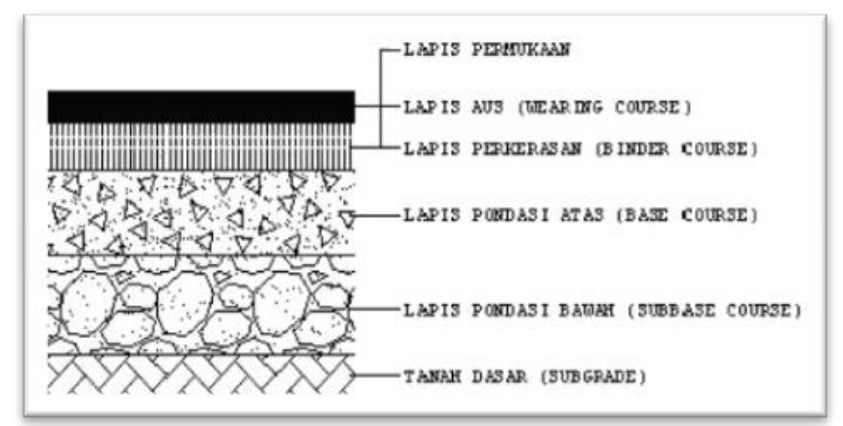

Gambar 2.1 Lapisan perkerasan lentur

\subsubsection{Perkerasan Kaku (Rigid pavement)}

Adalah perkerasan yang menggunakan bahan ikat aspal, yang sifatnya kaku. Perkerasan kaku berupa plat beton dengan atau tanpa tulangan diatas tanah dasar dengan atau tanpa pondasi bawah. Beban lalu lintas diteruskan keatas plat beton. Perkerasan kaku bisa dikelompokkan atas: 
1. Perkerasan kaku semen terbuat dari beton semen baik yang bertulang ataupun tanpa tulangan

2. Perkerasan kaku komposit yang terbuat dari komposit sehingga lebih kuat dari perkerasan semen, sehingga baik untuk digunakan pada landasan pesawat udara di Bandara.

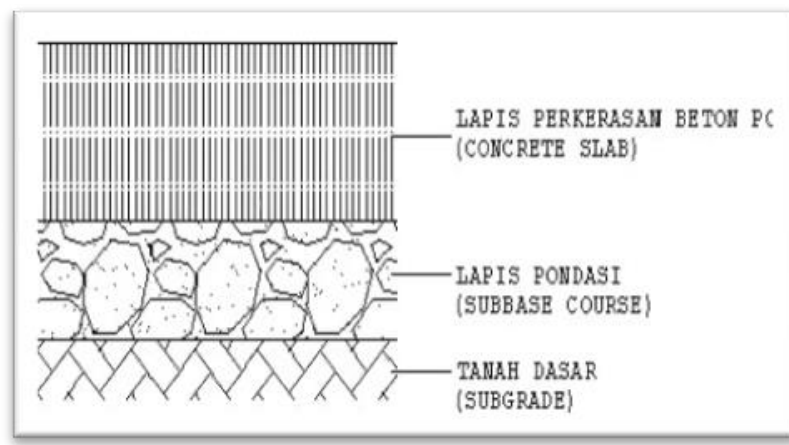

Gambar 2.2 Lapisan perkerasan kaku

\subsection{Kerusakan Perkerasan Lentur}

Pembagian tipe-tipe kerusakan umumnya berbeda-beda.Khusus untuk keperluan dalam hitungaan Indeks Kondisi Perkerasan (Pavement Condition Index, PCI, Shahin, 1994), disajikan tingkattingkat keparahan kerusakan.

Jenis-jenis kerusakan perkerasan lentur (aspal), umumnya dapat diklasifikasikan sebagai berikut :

1) Deformasi : bergelombang, alur, ambles, sungkur, mengembang benjol dan turun.

2) Retak : memanjang, melintang, diagonal, reflektif, blok, kulit buaya, dan bulan sabit.

3) Kerusakan tekstur permukaan: butiran lepas, kegemukan, agregat licin, terkelupas, dan stripping.

4) Kerusakan di pinggir perkerasan: pinggir retak/pecah dan bahu turun.

\subsection{Klassifikasi Kualitas Perkerasan dan Penentuan Jenis Pemeliharaan}

Dari nilai PCI masing-masing unit penelitian dapat diketahui kualitas lapis perkerasan untuk unit segmen berdasarkan kondisi tertentu yaitu sempurna (excellent), sangat baik (very good), baik (good), sedang (fair), jelek (poor), sangat jelek (very poor), dan gagal (failed). Adapun pembagian nilai kualitas kondisi perkerasan berdasarkan nilai PCI adalah sebagai berikut:

Tabel 2.1Klassifikasi Kondisi Perkerasan

(Sumber: Hary CH, Pemeliharaan Jalan, UGM PRESS, 2009)

\begin{tabular}{|c|c|}
\hline $\begin{array}{c}\text { Tingkat Kondisi } \\
\text { Perkerasan }\end{array}$ & $\begin{array}{c}\text { Rentang } \\
\text { Nilai }\end{array}$ \\
\hline $\begin{array}{c}\text { Sempurna } \\
\text { (Excellent) }\end{array}$ & $85-100$ \\
\hline $\begin{array}{c}\text { Sangat Baik (Very } \\
\text { Good) }\end{array}$ & $70-85$ \\
\hline Baik (Good) & $55-70$ \\
\hline Sedang (Fair) & $40-55$ \\
\hline Jelek (Poor) & $25-40$ \\
\hline $\begin{array}{c}\text { Sangat Jelek (Very } \\
\text { Poor ) }\end{array}$ & $10-25$ \\
\hline Gagal (Failed) & $0-10$ \\
\hline
\end{tabular}

Dari hasil klasifikasi kualitas perkerasan jalan ini, maka dapat ditentukan urutan jenis pemeliharaan yang sesuai untuk di lakukan. Jika nilai PCI $<50$ (untuk jalan primer), dan nilai PCI $<40$ (untuk jalan sekunder), maka diusulkan jenis pemeliharaan mayor yaitu pemeliharaan terhadap keseluruhan unit jalan melalui overlay atau rekonstruksi terhadap jalan tersebut. Sedangkan jika nilai PCI > 50 (untuk jalan primer, dan nilai PCI > 40 (untuk jalan sekunder) maka dapat dilakukan program pemeliharaan rutin sebagai usulan penanganannya.

\section{METODOLOGI PENELITIAN 3.1 Lokasi Penelitian}

Lokasi penelitian adalah ruas jalan Letjen Harun Sohar yang terletak di Kota Palembang, Provinsi Sumatera Selatan. Panjang ruas jalan yang distabilisasi adalah 
$3.220 \mathrm{~km}$ dan Lebar Ruas jalan yang distabilisasi adalah $10.3 \mathrm{~m}$ jalur kanan dan $10.06 \mathrm{~m}$ jalur kiri.

\subsection{Tahapan Penelitian}

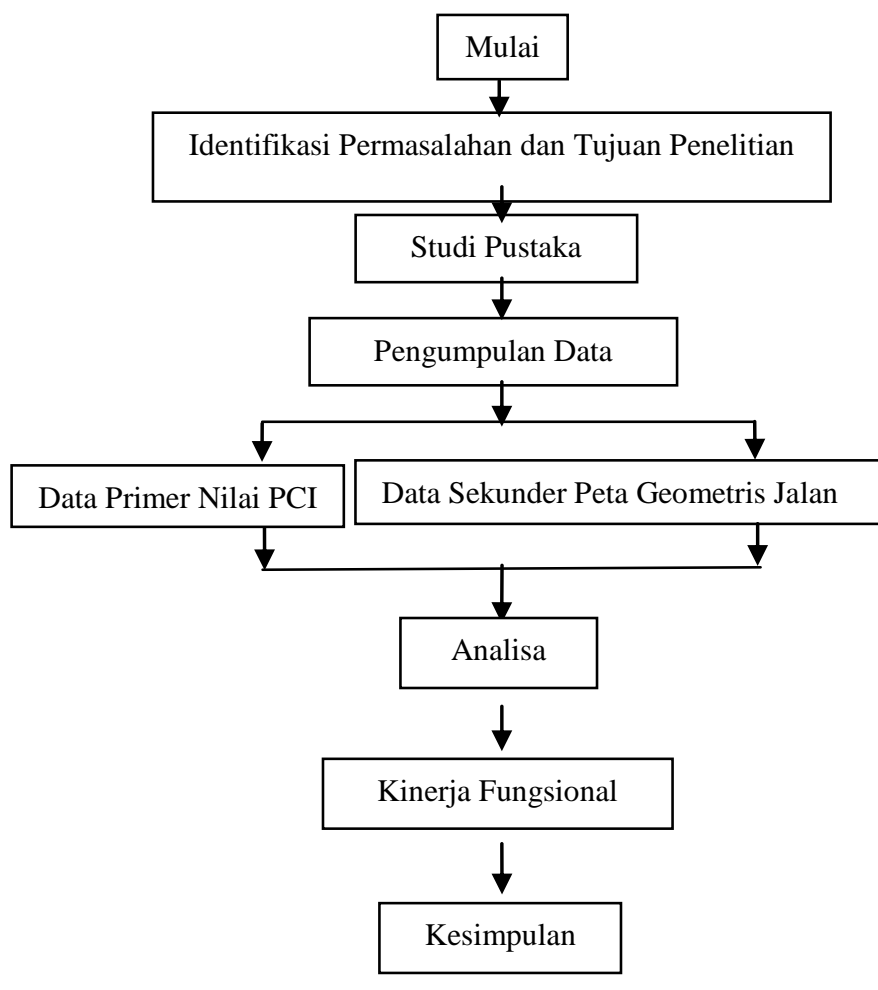

Gambar 3.1 Diagram Alir Penelitian

\subsection{Metode Pengumpulan Data}

Pengumpulan data merupakan suatu cara atau proses yang sistematis dalam pengumpulan, pencatatan, dan penyajian fakta untuk mencapai tujuan tertentu. Tujuan pengumpulan data dalam penelitian ini adalah untuk memperoleh faktor-faktor untuk melakukan analisa kinerja perkerasan jalan. Data yang diperlukan dalam penelitian ini berupa :
Tabel 3.1 Kebutuhan Data Penelitian

\begin{tabular}{|l|l|l|}
\hline Data Yang Diperlukan & $\begin{array}{l}\text { Metoda } \\
\text { Pengumpulan } \\
\text { Data }\end{array}$ & Sumber Data \\
\hline DATA PRIMER & & \\
\hline $\begin{array}{l}\text { Jenis dan Dimensi } \\
\text { Kerusakan Jalan (PCI) }\end{array}$ & Survei lapangan & Lapangan \\
\hline DATA SEKUNDER & & \\
\hline Peta dan Data Jalan & Studi dokumen & $\begin{array}{l}\text { SNVT P2JN } \\
\text { Sumatera } \\
\text { Selatan }\end{array}$ \\
\hline Hukum, peraturan dan \\
standard & Studi dokumen & $\begin{array}{l}\text { Pemerintah } \\
\text { pusat dan } \\
\text { daerah, } \\
\text { departemen, } \\
\text { badan } \\
\text { pemerintah, } \\
\text { lembaga non } \\
\text { pemerintah, dll. }\end{array}$ \\
\hline
\end{tabular}

\subsection{Metode PCI (PavementConditional Index)}

Penilaian kondisi kerusakan perkerasan yang dikembangkan oleh U.S. Army Corp of Enginerr (Shahin et al, 19761984), dinyatakan dalam Index Kondisi Pekerkerasan. Penggunaan PCI untuk perkerasan bandara, jalan, dan tempat parkir telah dipakai secara luas di Amerika.Metode PCI memberikan informasi kondisi perkerasan hanya pada saat survey dilakukan, tapi tidak dapat memberi gambaran prediksi di masa akan datang. Namun dengan demikian, dengan melakukan survey secara periodik, informasi kondisi perkerasan jalan dapat berguna untuk prediksi kinerja di masa datang, selain juga dapat digunakan sebagai masukan pengukur yang lebih detail.

\subsubsection{Penentuan Unit Sampel}

Unit sampel adalah bagian atau seksi dari suatu perkerasan yang didefinisikan hanya untuk keperluan pemeriksaan. Berikut ini akan disampaikan cara pembagian dan penentuan unit-unit sampel yang disurvei. 


\subsubsection{Cara Melakukan Survei Kondisi}

Perencanaan penelitian sebaiknya dilakukan supaya estimasi dapat ditentukan dengan memeriksa satu bagian unit-unit sampel didalam area penelitian. Penggunaan rencana penelitian secara statistik akan dapat mengurangi waktu yang dibutuhkan untuk memeriksa kondisi perkerasan dengan tanpa kehilangan keakuratan yang berakti. Penggunaan teori statistik hanya sebagai pilihan, dan pemeriksaan seluruh area penelitian lebih disarankan. Karna itu, harus dipertimbangkan dengan baik apakah penelitian secara statistik perlu dilakukan. Survei kondisi dilakukan pada seluruh perkerasan aspal, maupun aspal yang menutup perkerasan beton, adalah sebagai berikut (Shanin 1994). Adapun alat dan prosedur survei dijelaskan sebagai berikut :

1) Alat

personil pemeriksa memerlukan odometer tangan (hand odometer) untuk mengukur panjang dan luas kerusakan, penggaris untuk mengukur kedalaman alur atau amblas, dan manual kerusakan PCI.

2) Prosedur.

Satu unit sampel di periksa dengan mengukur tipe kerusakan dan tingkat kerusakannya, menurut manual PCI dan formulir data untuk lembar survei perkerasan lentur

Defenisi kerusakan dan klafikasi tingkat keparahan kerusakan serta kurva-kurva nilai pengurangan (deduct value). Definisi-definisi harus diikuti sedekat mungkin, jika melakukan survei PCI. Tulisan, rendah (low, L) sedang (medium, $\mathrm{M}$ ), atau tinggi $\mathrm{H}$ ). Dimasukkan dengan nomor kerusakan untuk mengindikasikan tingkat parahnya kerusakan.

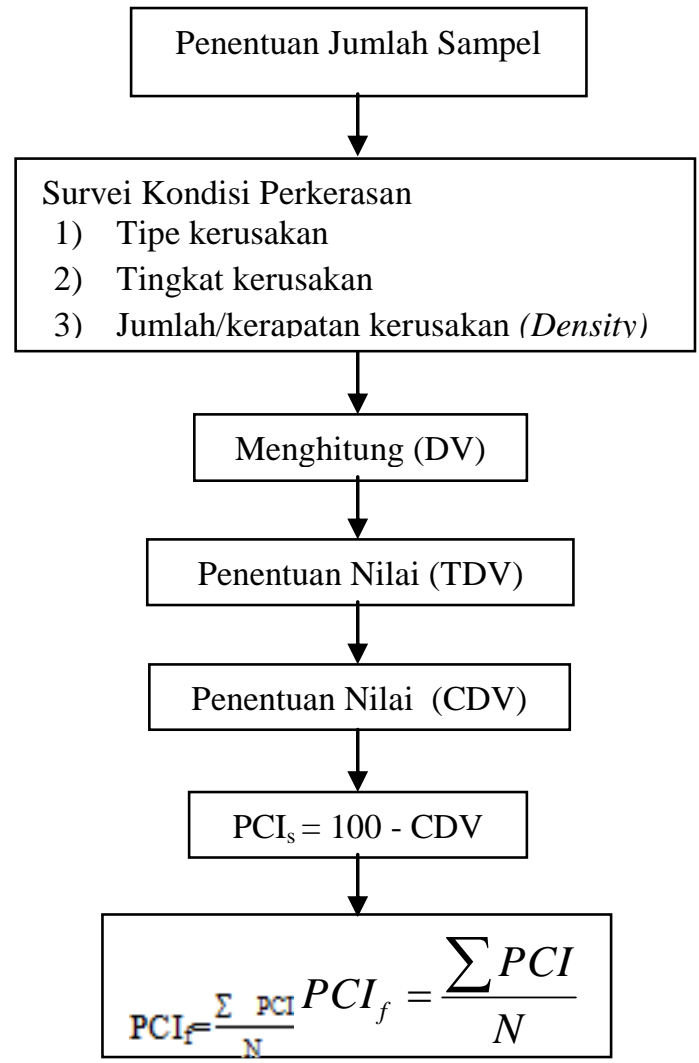

Gambar 3.2 Program Alir Survei

\section{ANALISA DAN PEMBAHASAN 4.1 Pengumpulan Data}

Pengumpulan data dilakukan di sepanjang ruas jalan Letjen Harun Sohar Palembang. Data yang diambil berupa data kondisi ruas jalan dan data kerusakan jalan.

\subsubsection{Data Kondisi Ruas Jalan}

Data kondisi ruas jalan ini meliputi :

1. Panjang ruas jalan yang dijadikan objek penelitian adalah sepanjang 3.233 kilometer, dimulai dari Simpang Lampu Merah TAA sampai dengan Simpang Pertigaan Bandara SMB II.

2. Ruas jalan Letjen Harun Sohar ini terdiri dari 2 jalur dan 3 lajur dengan bahu jalan dan median.

3. Untuk menganalisa kondisi perkerasan jalan maka panjang jalan 3.233 
kilometer dibagi ke dalam beberapa segmen.

\subsubsection{Penentuan Sampel PCI}

Berdasarkan tabel 4.1 unit sample $(\mathrm{N})=34$, standar deviasi (s) untuk perkerasan aspal $=10$, dan nilai kesalahan yang di ijinkan $(e)=5$, maka didapat jumlah minimum unit sample yang ditinjau dengan menggunakan rumus:

$$
\begin{gathered}
n=\frac{\mathrm{Ns}^{2}}{\mathrm{e}^{2}(N .1) s^{2}} \\
n=\frac{34 \times 10^{2}}{5^{2}{ }_{4}(34.1) 10^{2}}=11.1
\end{gathered}
$$

Tabel 4.1 Penentuan Unit Sampel Pada Pos 1 Jalur I

\begin{tabular}{|c|c|}
\hline \multicolumn{1}{|c|}{ Segmen } & Lebar Jalur $(\mathrm{m})$ \\
\hline 1 & 10,6 \\
\hline 2 & 10,6 \\
\hline 3 & 10,6 \\
\hline 5 & 10,6 \\
\hline 6 & 10,6 \\
\hline 7 & 10,6 \\
\hline 8 & 10,6 \\
\hline 9 & 10,6 \\
\hline \multicolumn{1}{|c|}{ Jumlah } & 10,6 \\
\hline \multicolumn{1}{|c|}{ Rata-Rata } & 96,4 \\
\hline Panjang Jalur (m) & 3233 \\
\hline Luas Jalur (m $\left.{ }^{2}\right)$ & 34629,022 \\
\hline $\begin{array}{l}\text { Syatar Luasan } \\
\text { Sampel (m }{ }^{2} \text { ) }\end{array}$ & $305-762$ \\
\hline $\begin{array}{l}\text { Luas Sampel (m } \\
\text { panjang 50 m }\end{array}$ & 535,56 \\
\hline Jumlah Sampel Unit & 64,66 \\
\hline $\begin{array}{l}\text { Distribusi Sampel } \\
\text { Jumlah Sampel } \\
\text { Total }\end{array}$ & 64 unit P $=50 \mathrm{~m}$ \\
\hline Unit Sampel disurvei & 65 unit \\
\hline Interval & 10 unit \\
\hline
\end{tabular}

Tabel 4.2 Penentuan Unit Sampel Pada Pos 2 Jalur II

\begin{tabular}{|c|c|}
\hline \multicolumn{1}{|c|}{ Segmen } & Lebar Jalur $(\mathrm{m})$ \\
\hline 1 & 11,03 \\
\hline 2 & 9,9 \\
\hline 3 & 10,3 \\
\hline 5 & 10,3 \\
\hline 6 & 10,3 \\
\hline 7 & 9,9 \\
\hline 8 & 10,3 \\
\hline 9 & 10,3 \\
\hline \multicolumn{1}{|c|}{ Jumlah } & 10,3 \\
\hline \multicolumn{1}{|c|}{ Rata-Rata } & 92,63 \\
\hline Panjang Jalur (m) & 3233 \\
\hline Luas Jalur (m $\left.{ }^{2}\right)$ & 33274,754 \\
\hline $\begin{array}{l}\text { Syatar Luasan } \\
\text { Sampel (m }{ }^{2} \text { ) }\end{array}$ & $305-762$ \\
\hline $\begin{array}{l}\text { Luas Sampel (m } \\
\text { panjang 50 m }\end{array}$ & 514,61 \\
\hline Jumlah Sampel Unit & 64,66 \\
\hline \begin{tabular}{l} 
Distribusi Sampel \\
\hline $\begin{array}{l}\text { Jumlah Sampel } \\
\text { Total }\end{array}$
\end{tabular} & 64 unit P $=50 \mathrm{~m}$ \\
\hline Unit Sampel disurvei & 65 unit \\
\hline Interval \\
\hline
\end{tabular}

\subsubsection{Data Kondisi Kerusakan Jalan}

Data kondisi kerusakan jalan meliputi data panjang, lebar, luasan serta kedalaman dari tiap-tiap jenis kerusakan yang terjadi pada perkerasan jalan. Data luas kerusakan yang terjadi pada ruas jalan Letjen Harun Sohar ini direkapitulasi masing-masing setiap 50 meter. Selanjutnya akan dilakukan pengolahan data dengan metode PCI (Pavement Condition Index).

Berikut adalah hasil analisa data tiap unit sampel dan perkerusakan. 
Tabel 4.3 Persentase Kerusakan Existing Pos 1

\begin{tabular}{|l|c|c|}
\hline $\begin{array}{c}\text { Jenis } \\
\text { kerusakan }\end{array}$ & Luas $\left(\mathbf{m}^{2)}\right.$ & $\begin{array}{c}\% \\
\text { Kerusakan }\end{array}$ \\
\hline $\begin{array}{l}\text { Tambalan } \\
\text { Galian }\end{array}$ & 7.47 & 74.70 \\
\hline $\begin{array}{l}\text { Retak Kulit } \\
\text { Buaya }\end{array}$ & 1.55 & 15.4 \\
\hline Lubang & 1 & 10 \\
\hline $\begin{array}{l}\text { Jumlah Total } \\
\text { Kerusakan }\end{array}$ & 101.157 & 100 \\
\hline
\end{tabular}

Tabel 4.4 Persentase Kerusakan Existing Pos 2

\begin{tabular}{|l|c|c|}
\hline Jenis kerusakan & Luas $\left(\mathbf{m}^{2)}\right.$ & $\begin{array}{c}\text { \% } \\
\text { Kerusakan }\end{array}$ \\
\hline Benjol dan Turun & 36.96 & 14.59 \\
\hline Tambalan Galian & 142.81 & 56.35 \\
\hline Retak Pinggir & 9.6 & 3.8 \\
\hline $\begin{array}{l}\text { Pelapukan/Butiran } \\
\text { Lepas }\end{array}$ & 47.40 & 18.70 \\
\hline Lubang & 1 & 0.40 \\
\hline Retak Blok & 2.38 & 0.94 \\
\hline $\begin{array}{l}\text { Retak Kulit Buaya } \\
\text { Retak Memanjang }\end{array}$ & 11,81 & 4.66 \\
\hline $\begin{array}{c}\text { Jumlah Total } \\
\text { Kerusakan }\end{array}$ & 253.48 & 100 \\
\hline
\end{tabular}

\subsection{Penentuan Nilai Density (Kerapatan) \\ Density (kerapatan adalah luas atau} panjang total dari satu jenis kerusakan terhadap luas panjang total bagian jalan yang diukur, bisa dalam sq,sf atau $\mathrm{m}^{2}$, atau dalam feet atau meter.

Kerapatan (density) $(\%)=\frac{\mathrm{Ad}}{\mathrm{As}} \times 100 \%$
Tabel 4.5 Nilai Pada Formulir Survey Pos 1

\begin{tabular}{|c|c|c|c|c|c|}
\hline \multicolumn{6}{|c|}{$\begin{array}{l}\text { Luas Sampel }\left(\mathrm{m}^{2}\right) 535,56 \\
\text { Panajang } 50 \mathrm{~m}\end{array}$} \\
\hline No & $\begin{array}{c}\text { Jenis } \\
\text { Kerusakan }\end{array}$ & Sampel & $\begin{array}{c}\text { Luas total jenis } \\
\text { kerusakan }\end{array}$ & Density & (DV) \\
\hline 1 & $\begin{array}{l}\text { Tamalan } \\
\text { Galian }\end{array}$ & \multirow[t]{2}{*}{6} & 1.17 & 0.218463 & \\
\hline & Lubang & & 0.42 & 0.18672 & \\
\hline 2 & $\begin{array}{l}\text { Tambalan } \\
\text { Galian }\end{array}$ & 12 & 37.125 & 0.078423 & \\
\hline 3 & $\begin{array}{l}\text { Tidak Ada } \\
\text { Kerusakan }\end{array}$ & 18 & & & \\
\hline 4 & $\begin{array}{l}\text { Tambalan } \\
\text { Galian }\end{array}$ & 24 & 37.125 & 0.6932 & \\
\hline 5 & $\begin{array}{l}\text { Tidak Ada } \\
\text { Kerusakan }\end{array}$ & 30 & & & \\
\hline 6 & $\begin{array}{l}\text { Tidak Ada } \\
\text { Kerusakan }\end{array}$ & 36 & & & \\
\hline \multirow[t]{2}{*}{7} & $\begin{array}{l}\text { Tambalan } \\
\text { Galian }\end{array}$ & \multirow[b]{2}{*}{42} & 22.632 & 0.422586 & \\
\hline & $\begin{array}{l}\text { Retak } \\
\text { Kulit } \\
\text { Buaya }\end{array}$ & & 1.55 & 0.289417 & \\
\hline 8 & $\begin{array}{l}\text { Tidak Ada } \\
\text { Kerusakan }\end{array}$ & 48 & & & \\
\hline 9 & $\begin{array}{l}\text { Tidak Ada } \\
\text { Kerusakan }\end{array}$ & 54 & & & \\
\hline 10 & $\begin{array}{l}\text { Tidak Ada } \\
\text { Kerusakan }\end{array}$ & 60 & & & \\
\hline
\end{tabular}

Tabel 4.6 Nilai Pada Formulir Survey Pos 2

\begin{tabular}{|c|c|c|c|c|c|}
\hline \multicolumn{6}{|c|}{$\begin{array}{l}\text { Luas Sampel }\left(\mathrm{m}^{2}\right) 535,56 \\
\text { Panajang } 50 \mathrm{~m}\end{array}$} \\
\hline No & $\begin{array}{c}\text { Jenis } \\
\text { Kerusakan } \\
\end{array}$ & Sampel & $\begin{array}{c}\text { Luas total jenis } \\
\text { kerusakan }\end{array}$ & Density & (DV) \\
\hline \multirow[t]{2}{*}{1} & $\begin{array}{l}\text { Benjol dan } \\
\text { Turun }\end{array}$ & \multirow[t]{2}{*}{6} & 3.475 & 0.675269 & \\
\hline & $\begin{array}{l}\text { Tamalan } \\
\text { Galian }\end{array}$ & & 47.6 & 9.249 .723 & \\
\hline 2 & $\begin{array}{l}\text { Retak } \\
\text { Pinggir }\end{array}$ & 12 & 2.1 & 0.408076 & \\
\hline \multirow[t]{4}{*}{3} & $\begin{array}{l}\text { Benjol dan } \\
\text { Turun }\end{array}$ & \multirow{4}{*}{18} & 14.745 & 2.865 .277 & \\
\hline & $\begin{array}{l}\text { Benjol dan } \\
\text { Turun }\end{array}$ & & 18.742 & 3.641 .981 & \\
\hline & $\begin{array}{l}\text { Tambalan } \\
\text { Galian }\end{array}$ & & 12.44 & 2.417 .365 & \\
\hline & $\begin{array}{l}\text { Tambalan } \\
\text { Galian }\end{array}$ & & 41.6 & 8.083 .792 & \\
\hline 4 & $\begin{array}{l}\text { Tidak Ada } \\
\text { Kerusakan }\end{array}$ & 24 & & & \\
\hline \multirow[t]{2}{*}{5} & $\begin{array}{l}\text { Tambalan } \\
\text { Galian }\end{array}$ & \multirow{2}{*}{30} & 6.64 & 1.290 .298 & \\
\hline & $\begin{array}{l}\text { Pelapukan } \\
\text { dan Butiran }\end{array}$ & & 21.14 & 4.107 .965 & \\
\hline \multirow[t]{3}{*}{6} & Lubang & \multirow{3}{*}{36} & 1 & 0.94322 & \\
\hline & $\begin{array}{l}\text { Retak } \\
\text { Pinggir }\end{array}$ & & 2.6 & 0.505237 & \\
\hline & Retak Blok & & 23.761 & 0.461709 & \\
\hline 7 & $\begin{array}{l}\text { Retak Kulit } \\
\text { Buaya }\end{array}$ & 42 & 7.975 & 1.549 .717 & \\
\hline \multirow[t]{2}{*}{8} & $\begin{array}{l}\text { Tambalan } \\
\text { Galian }\end{array}$ & \multirow{2}{*}{48} & 18.837 & 3.660 .442 & \\
\hline & $\begin{array}{l}\text { Tambalan } \\
\text { Galian }\end{array}$ & & 15.75 & 306.057 & \\
\hline
\end{tabular}




\begin{tabular}{|c|l|c|c|c|c|}
\hline & $\begin{array}{l}\text { Retak Kulit } \\
\text { Buaya }\end{array}$ & & 3.84 & 0.746196 & \\
\cline { 4 - 6 } & $\begin{array}{l}\text { Retak } \\
\text { Pinggir }\end{array}$ & 4.9 & 0.952177 & \\
\hline 9 & $\begin{array}{l}\text { Retak } \\
\text { Memanjang }\end{array}$ & 54 & 1.5 & 0.291477 & \\
\hline 10 & $\begin{array}{l}\text { Pelapukan } \\
\text { dan Butiran }\end{array}$ & 60 & 261.665 & 5.104 .157 & \\
\hline
\end{tabular}

\subsection{Menghitung Deduct Value (DV)}

Penentuan nilai pengurangan $D V$ (Deduct Value) untuk tiap kombinasi tipe kerusakan dan tingkat keparahan dari kurva nilai pengurangan kerusakan.

1. Hasil dari pengurangan Deduct Value dengan menggunakan Grafik (kurva) hitungan PCI dengan permukaan perkerasan aspal pada POS 1 .

a) Segmen 06

a. Untuk jenis kerusakan Tambalan dan Tambalan Galian. Dengan nilai Density 0.218463

b. Untuk jenis kerusakan Lubang. Dengan nilai Density 0.18

b) Segmen 12

a. Untuk jenis kerusakan Tambalan dan Tambalan Galian. Dengan nilai Density 0.07842

c) Segmen 24

a. Untuk jenis kerusakan Tambalan dan Tambalan Galian. Dengan nilai Density 0.6932

d) Segmen 42

a. Untuk jenis kerusakan Tambalan dan Tambalan Galian. Dengan nilai Density 0.4225

b. Untuk jenis kerusakan Retak Kulit Buaya. Dengan nilai Density 0.2894

2. Hasil dari pengurangan Deduct Value dengan menggunakan Grafik (kurva) hitungan PCI dengan permukaan perkerasan aspal pada POS 1 .

a) Segmen 06

a. Untuk jenis kerusakan Benjol dan Turun. Dengan nilai Density 0.672569

b. Untuk jenis kerusakan Tambalan dan Tambalan Galian. Dengan nilai Density 9.249723 b) Segmen 12

a. Untuk jenis kerusakan Retak Pinggir. Dengan nilai Density 0.408076

c) Segmen 18

a. Untuk jenis kerusakan Benjol dan Turun. Dengan nilai Density 2.865277

b. Untuk jenis kerusakan Benjol dan Turun. Dengan nilai Density 3.641981

c. Untuk jenis kerusakan Tambalan dan Tambalan Galian. Dengan nilai Density 2.417365

d. Untuk jenis kerusakan Tambalan dan Tambalan Galian. Dengan nilai Density 8.083792

d) Segmen 30

a. Untuk jenis kerusakan Tambalan dan Tambalan Galian. Dengan nilai Density 1.290298

b. Untuk jenis kerusakan Pelapikan dan Butiran Lepas. Dengan nilai Density 9.249723

e) Segmen 36

a. Untuk jenis kerusakan Lubang. Dengan nilai Density 0.94322

b. Untuk jenis kerusakan Retak Pinggir. Dengan nilai Density 0.505237

c. Untuk jenis kerusakan Retak Blok. Dengan nilai Density 0.461709

f) Segmen 42

a. Untuk jenis kerusakan Retak Kulit Buaya. Dengan nilai Density 1.539717

g) Segmen 48

a. Untuk jenis kerusakan Tambalan dan Tambalan Galian. Dengan nilai Density 3.660442

b. Untuk jenis kerusakan Tambalan dan Tambalan Galian. Dengan nilai Density 3.06057

c. Untuk jenis kerusakan Retak Kulit Buaya. Dengan nilai Density 0.746196

d. Untuk jenis kerusakan Retak Pinggir. Dengan nilai Density 0.952177

h) Segmen 54

a. Untuk jenis kerusakan Retak Kulit Buaya. Dengan nilai Density 0.291477

i) Segmen 60

a. Untuk jenis kerusakan Retak Kulit Buaya. Dengan nilai Density 26.2665 


\subsection{Penentuan Nilai Total Deduct Value}

Penentuan nilai pengurangan TDV (Total Deduct Value) untuk tiap kombinasi tipe kerusakan dan tingkat keparahan dari hasil nilai yang di dapat pada kurva penilaian kerusakan.

Tabel 4.6 Nilai Total Deduct Value Pos 1

\begin{tabular}{|c|c|c|c|}
\hline \multicolumn{4}{|c|}{ SEGMEN 6} \\
\hline $\begin{array}{c}\text { Jenis } \\
\text { Kerusakan }\end{array}$ & Density \% & $\begin{array}{c}\text { Tingkat } \\
\text { Kerusakan }\end{array}$ & $\begin{array}{c}\text { Deduct } \\
\text { Value }\end{array}$ \\
\hline $\begin{array}{l}\text { Tambalan } \\
\text { Galian }\end{array}$ & 0.218463 & $\mathrm{~L}$ & 0 \\
\hline Lubang & 0.18672 & $\mathrm{~L}$ & 5.5 \\
\hline TOTAL & DEDUCT I & VALUE & 5.5 \\
\hline \multicolumn{4}{|c|}{ SEGMEN 12} \\
\hline $\begin{array}{l}\text { Jenis } \\
\text { Kerusakan }\end{array}$ & Density \% & $\begin{array}{c}\text { Tingkat } \\
\text { Kerusakan }\end{array}$ & $\begin{array}{c}\text { Deduct } \\
\text { Value }\end{array}$ \\
\hline $\begin{array}{l}\text { Tambalan } \\
\text { Galian }\end{array}$ & 0.078423 & $\mathrm{M}$ & 4.5 \\
\hline TOTAL & DEDUCT I & VALUE & 4.5 \\
\hline \multicolumn{4}{|c|}{ SEGMEN 24} \\
\hline $\begin{array}{l}\text { Jenis } \\
\text { Kerusakan }\end{array}$ & Density \% & $\begin{array}{c}\text { Tingkat } \\
\text { Kerusakan }\end{array}$ & $\begin{array}{c}\text { Deduct } \\
\text { Value }\end{array}$ \\
\hline $\begin{array}{l}\text { Tambalan } \\
\text { Galian }\end{array}$ & 0.6932 & $\mathrm{~L}$ & 0 \\
\hline TOTAL & DEDUCT I & VALUE & 0 \\
\hline \multicolumn{4}{|c|}{ SEGMEN 42} \\
\hline $\begin{array}{l}\text { Jenis } \\
\text { Kerusakan }\end{array}$ & Density \% & $\begin{array}{c}\text { Tingkat } \\
\text { Kerusakan }\end{array}$ & $\begin{array}{c}\text { Deduct } \\
\text { Value }\end{array}$ \\
\hline $\begin{array}{l}\text { Tambalan } \\
\text { Galian }\end{array}$ & 0.422586 & $\mathrm{~L}$ & 0 \\
\hline $\begin{array}{l}\text { Retak Kulit } \\
\text { Buaya }\end{array}$ & 9.289 .417 & $\mathrm{~L}$ & 4.6 \\
\hline \multicolumn{3}{|c|}{ TOTAL DEDUCT VALUE } & 4.6 \\
\hline
\end{tabular}

Tabel 4.7 Nilai Total Deduct Value Pos 1

\begin{tabular}{|c|c|c|c|}
\hline \multicolumn{4}{|c|}{ SEGMEN 6} \\
\hline $\begin{array}{c}\text { Jenis } \\
\text { Kerusakan }\end{array}$ & Density \% & $\begin{array}{c}\text { Tingkat } \\
\text { Kerusakan }\end{array}$ & $\begin{array}{c}\text { Deduct } \\
\text { Value }\end{array}$ \\
\hline $\begin{array}{c}\text { Benjol dan } \\
\text { Turun }\end{array}$ & 0.675269 & $\bar{M}$ & 15 \\
\hline $\begin{array}{l}\text { Tambalan } \\
\text { Galian }\end{array}$ & 9.249 .723 & $\overline{\mathrm{L}}$ & 14 \\
\hline TOTAL & DEDUCT & VALUE & 29 \\
\hline \multicolumn{4}{|c|}{ SEGMEN 12} \\
\hline $\begin{array}{c}\text { Jenis } \\
\text { Kerusakan }\end{array}$ & Density \% & $\begin{array}{c}\text { Tingkat } \\
\text { Kerusakan }\end{array}$ & $\begin{array}{l}\text { Deduct } \\
\text { Value }\end{array}$ \\
\hline $\begin{array}{c}\text { Retak } \\
\text { Pinggir }\end{array}$ & 0.408076 & $\mathrm{~L}$ & 2 \\
\hline TOTAL & DEDUCT & VALUE & 2 \\
\hline \multicolumn{4}{|c|}{ SEGMEN 18} \\
\hline $\begin{array}{c}\text { Jenis } \\
\text { Kerusakan }\end{array}$ & Density \% & $\begin{array}{c}\text { Tingkat } \\
\text { Kerusakan }\end{array}$ & $\begin{array}{l}\text { Deduct } \\
\text { Value }\end{array}$ \\
\hline \begin{tabular}{|c|} 
Benjol dan \\
Turun
\end{tabular} & 2.865 .277 & $\mathrm{H}$ & 62 \\
\hline \begin{tabular}{|c} 
Benjol dan \\
Turun
\end{tabular} & 3.641 .981 & M & 37 \\
\hline $\begin{array}{c}\text { Tambalan } \\
\text { Galian }\end{array}$ & 2.417 .365 & $\bar{M}$ & 12 \\
\hline \begin{tabular}{|c|} 
Tambalan \\
Galian
\end{tabular} & 8.083 .792 & $\mathrm{~L}$ & 12 \\
\hline TOTAL & DEDUCT & VALUE & 123 \\
\hline \multicolumn{4}{|c|}{ SEGMEN 30} \\
\hline $\begin{array}{c}\text { Jenis } \\
\text { Kerusakan }\end{array}$ & Density \% & $\begin{array}{c}\text { Tingkat } \\
\text { Kerusakan }\end{array}$ & $\begin{array}{l}\text { Deduct } \\
\text { Value }\end{array}$ \\
\hline $\begin{array}{c}\text { Tambalan } \\
\text { Galian }\end{array}$ & 1.290 .298 & $\mathrm{M}$ & 10 \\
\hline $\begin{array}{c}\text { Pelapukan } \\
\text { Butiran }\end{array}$ & 4.107 .965 & $\mathrm{~L}$ & 3 \\
\hline TOTAL & DEDUCT & VALUE & 13 \\
\hline \multicolumn{4}{|c|}{ SEGMEN 36} \\
\hline $\begin{array}{c}\text { Jenis } \\
\text { Kerusakan }\end{array}$ & Density \% & $\begin{array}{c}\text { Tingkat } \\
\text { Kerusakan }\end{array}$ & $\begin{array}{l}\text { Deduct } \\
\text { Value }\end{array}$ \\
\hline Lubang & 1 & $\mathrm{~L}$ & 17 \\
\hline $\begin{array}{c}\text { Retak } \\
\text { Pinggir }\end{array}$ & 0.505237 & $\bar{L}$ & 2 \\
\hline Retak Blok & 0.461709 & $\mathrm{~L}$ & 0 \\
\hline \multicolumn{3}{|c|}{ TOTAL DEDUCT VALUE } & 19 \\
\hline
\end{tabular}




\begin{tabular}{|c|c|c|c|}
\hline \multicolumn{4}{|c|}{ SEGMEN 42} \\
\hline $\begin{array}{c}\text { Jenis } \\
\text { Kerusakan }\end{array}$ & Density \% & $\begin{array}{c}\text { Tingkat } \\
\text { Kerusakan }\end{array}$ & $\begin{array}{c}\text { Deduct } \\
\text { Value }\end{array}$ \\
\hline $\begin{array}{c}\text { Retak Kulit } \\
\text { Buaya }\end{array}$ & $1 . .549717$ & $\overline{\mathrm{L}}$ & 22 \\
\hline TOTAL & DEDUCT & VALUE & 22 \\
\hline \multicolumn{4}{|c|}{ SEGMEN 48} \\
\hline $\begin{array}{c}\text { Jenis } \\
\text { Kerusakan }\end{array}$ & Density \% & $\begin{array}{c}\text { Tingkat } \\
\text { Kerusakan }\end{array}$ & $\begin{array}{c}\text { Deduct } \\
\text { Value }\end{array}$ \\
\hline $\begin{array}{c}\text { Tambalan } \\
\text { Galian }\end{array}$ & 3.660 .442 & $\overline{\mathrm{H}}$ & 28 \\
\hline $\begin{array}{c}\text { Tambalan } \\
\text { Galian }\end{array}$ & 306.057 & $\bar{L}$ & 4 \\
\hline $\begin{array}{c}\text { Retak Kulit } \\
\text { Buaya }\end{array}$ & 0.746196 & $\bar{M}$ & 7 \\
\hline $\begin{array}{c}\text { Retak } \\
\text { Pinggir }\end{array}$ & 0.952177 & $\mathrm{~L}$ & 4 \\
\hline TOTAL & DEDUCT & VALUE & 43 \\
\hline \multicolumn{4}{|c|}{ SEGMEN 54} \\
\hline $\begin{array}{c}\text { Jenis } \\
\text { Kerusakan }\end{array}$ & Density \% & \begin{tabular}{|c|} 
Tingkat \\
Kerusakan
\end{tabular} & $\begin{array}{c}\text { Deduct } \\
\text { Value }\end{array}$ \\
\hline $\begin{array}{c}\text { Retak } \\
\text { Memanjang }\end{array}$ & 0.291477 & $\mathrm{~L}$ & 0 \\
\hline TOTAL & DEDUCT & ALUE & 0 \\
\hline \multicolumn{4}{|c|}{ SEGMEN 60} \\
\hline $\begin{array}{c}\text { Jenis } \\
\text { Kerusakan }\end{array}$ & Density \% & $\begin{array}{c}\text { Tingkat } \\
\text { Kerusakan }\end{array}$ & $\begin{array}{c}\text { Deduct } \\
\text { Value }\end{array}$ \\
\hline $\begin{array}{c}\text { Pelapukan } \\
\text { Butiran }\end{array}$ & 262.665 & $\mathrm{~L}$ & 3 \\
\hline \multicolumn{3}{|c|}{ TOTAL DEDUCT VALUE } & 3 \\
\hline
\end{tabular}

\subsection{Perhitungan Nilai Pavement Conditional Index (PCI)}

Menghitung nilai Pavement

Conditional Index (PCI) dengan menggunakan Rumus : PCI 100 - CDV.
Tabel 4.8 Analisa PCI

\begin{tabular}{|c|c|c|}
\hline \multicolumn{3}{|c|}{ ANALISA PCI } \\
\hline SEGMEN & CDV & PCI \\
\hline 6 & 5.5 & 94.5 \\
\hline 12 & 4.5 & 94.5 \\
\hline 18 & 0 & 100 \\
\hline 24 & 0 & 100 \\
\hline 30 & 0 & 100 \\
\hline 36 & 0 & 100 \\
\hline 42 & 4.6 & 95.4 \\
\hline 48 & 0 & 100 \\
\hline 54 & 0 & 100 \\
\hline 60 & 0 & 100 \\
\hline \multicolumn{2}{|c|}{ TOTAL } & 98.54 \\
\hline SEGMEN & $\mathrm{CDV}$ & PCI \\
\hline 6 & 10 & 90 \\
\hline 12 & 2 & 98 \\
\hline 18 & 60 & 40 \\
\hline 24 & 0 & 100 \\
\hline 30 & 9 & 91 \\
\hline 36 & 12 & 88 \\
\hline 42 & 22 & 89 \\
\hline 48 & 22 & 78 \\
\hline 54 & 0 & 100 \\
\hline 60 & 0.3 & 99.7 \\
\hline \multicolumn{2}{|c|}{ TOTAL } & 87.37 \\
\hline
\end{tabular}

\section{PENUTUP}

\subsection{Kesimpulan}

Dari hasil nilai PCI rata-rata pada ruas Jalan Letjen Harun Sohar Palembang pada area Pos 1 adalah 98.54, sedangkan pada Pos 2 adalah 87.37. Dengan demikianmaka tingkat kondisi perkerasan pada ruas Jalan Letjen Harun Sohar Palembang adalah sempurna (excellent) dan sangat baik (very good). Dari hasil nilai rata-rata PCI tersebut dengan survei kondisi yang telah dilakukan dapat disimpulkan bahwa Jalan Letjen Harun Sohar Palembang tidak diperlukan perbaikan yang 
serius, hanya pemeliharaan rutin atau perawatannya saja yang harus dilakukan.

\section{DAFTAR PUSTAKA}

Hary Christady Hardiyatmo (2009), Pemeliharaan Jalan Raya, UGM, Gadjah Mada University Press.

Shahin, M. Y. (1994). Pavement Management for Airports, Roads, and Parking, Lots.Chapman \& Hall. New York.

Faiz Arif Harahap (2012), dengan penelitiannya "Analisa Kinerja Deep Lift Insitu Pavement dengan Metode IRI dan PCI. Universitas Sumatera Utara. 